\title{
The Problems of Talent Training in Higher Engineering Education and Strategies to Reform
}

\author{
Yinxia Wei ${ }^{1, a}$, Ying Peng ${ }^{2, b, *}$ \\ ${ }^{1}$ Dean's office ,Guilin University of Electronic Technology,Guiling, Guangxi, China \\ ${ }^{2}$ School of materials science and Engineering,Guilin University of Electronic Technology,Guiling, \\ Guangxi, China \\ a34221212@qq.com, ’mythmail@126.com \\ ${ }^{*}$ Corresponding author
}

\begin{abstract}
Even though our country has the world's most abundant engineering students and a huge demand for talents, the problem on the disconnection between higher engineering education and industry still exists, which exerts a passive influence on the quality of talent training. The reform of higher engineering education should learn the engineering education experiences from abroad, and formulate the scientific and rational talent training mode in accordance with national conditions. Complying to the tides of international engineering education reform, this paper puts forward the important strategies and choices of China's engineering education reform, namely, educational concepts transfer from engineering science to engineering practice, teaching methods transfer from academy-oriented to project-oriented, the subject of talent training transfers from institutions of higher learning to the cooperation between production and learning.
\end{abstract}

Key words: higher engineering education,talent training, strategies of reform

\section{论高等工程教育人才培养存在的问题与改革策略 \\ 魏银霞 ${ }^{1, a}$, 彭英 ${ }^{2, b},{ }^{*}$ \\ ${ }^{1}$ 桂林电子科技大学教务处, 桂林, 广西, 中国 \\ ${ }^{2}$ 桂林电子科技大学材料科学与工程学院, 桂林, 广西, 中国 \\ a34221212@qq.com, ’mythmail@126.com}

*通讯作者

中文摘要. 我国拥有全球最充足的工科生 源和巨大的人才需求市场,但高等工程教育 存在着与产业脱节的问题, 严重影响人才培 养质量。高等工程教育改革需要借鉴国外工

程教育经验, 制定出符合国情、科学合理的 人才培养模式。本文从国际工程教育改革潮 流提出改革我国工程教育的重要策略选择: 教育理念从工程科学回归到工程实际、教学 
模式以学科为导向转向以项目实现为导向、 人才培养主体以高校为主转向产学合作。 关键词: 高等工程教育; 人才培养; 改革战 略

\section{1. 引言}

高等工程教育是以科学技术为主要学 科基础、以培养能将科学技术转化为生产力 的工程师为目标的专门教育。高等工程教育 在中国已有百年以上历史。1 895 年天津成 立的北洋大学、1896 年在上海成立的南洋 公学和唐山路矿学院可以说是我国最早培 养科技人才的大学。新中国成立以后, 高等 工程教育得到了飞速发展, 特别是改革开放 以来，国家大力支持高等教育，形成了庞大 的分层次的教育体系, 改革开放以来, 国家 大力支持高等教育, 形成了庞大的分层次的 教育体系, 培养了数以万计的专业技术人 才, 适应了工业社会对工程科技人才的需 求, 推动了国家的工业化发展。目前国内工 程技术人员队伍日益壮大,工科毕业生规模 世界第一, 然而随着高校毕业生就业问题凸 显的情形下高等工程人才培养质量受到社 会各界脈病。主要表现在工科专业人才培养 同质化, 大学生培养质量不高, 适用性不强, 不能适应社会企业需求。

\section{2. 工程教育人才培养问题分析}

目前工程教育无论在教育理念、培养目 标、课程体系、实践教学甚至师资队伍等方 面均存在问题, 导致人才培养模式单一化、 培养内容同质化。

\section{1 培养目标定位不清: 培养科学家还是 工程师}

所谓培养目标, 是指学校根据教育目的 制定的具体人才培养质量规格, 是把学生塑 造成什么样的人的一种预期和规定。培养目 标对人才培养活动具有导向和评价作用。高 校人才培养目标定位不准确, 人才培养活动 就会走入误区 ${ }^{1}$ 。广大工科高校的培养目标 究竟是培养科学家还是培养工程师? 这是 高校首先要解决的问题。培养目标的不同定
位造成教育实践的截然不同: 以培养工程师 为目的的工程教育强调理论应用于实践, 着 重培养学生的实际动手能力; 而以培养科学 家为目的的科学教育强调理论知识体系的 完善, 着重培养学生的科学思维能力。

新中国成立后, 我国引进了前苏联专业 教育模式, 以培养某一方面的工程师、专家 为主, 但存在过于重视学科体系、专业划分 过细过窄的弊端。改革开放以后, 经过反思 转而学习美国的教育制度, 把工科培养目标 调整为工学学士、硕士和博士, 以培养专业 型、研究型人才为主, 辅以应用型人才培养。 却又进入另一个误区。长期以来, 高校对工 程教育的本质理解不清楚, 以科学教育的模 式来实施工程教育。不同类型高校从教育部 重点大学到普通地方院校, 从研究型大学到 一般教学型高校都在实施相似的 (科学型人 才）培养目标、课程体系、教学方法和管理 制度。人才培养模式单一, 致使毕业生的社 会适应性比较差。

\section{2 培养过程脱离产业: 关门办学还是 面向产业}

作为培养高级人才的摇篮, 大多数大学 还是沿袭过去的精英教育培养模式, 依据预 先设定好的计划培养学生。培养方案普遍缺 乏企业界、工程界的参与, 基本四年一个培 养周期不变, 难以适应产业结构的调整和科 学技术日新月异的变化; 高校一般设置了本 科教学指导委员会, 指导本校教学改革, 但 委员构成基本为本校教师, 鲜有行业和企业 的代表; 工科专业课程体系偏重理论, 更多 强调学科体系的系统性, 知识结构侧重 “工 程科学” 而非 “工程应用”, 学生职业素养 缺乏; 教学内容陈旧, 全国不同类型高校很 多使用同一本教材,一些经典教材内容甚至 十几年不变。例如在计算机教学领域, 许多 教材难以及时跟上技术形势, 学生毕业后发 现公司采用的技术和大学所学的内容存在 很大差距。整体上工科高校培养方案和培养 模式与社会脱节, 毕业生必然难以满足产业 需求 ${ }^{2}$ 。 


\section{3 实践教学环节缺乏: 理论与实践孰轻 孰重}

受传统课程论的影响, 我国一向重理论 课程, 轻实践课程; 重理论知识传授, 轻应 用能力培养。高等教育大众化以后, 学生规 模扩大, 优质教学资源短缺, 高校实验条件 不足, 批量实验方式造成学生忙于应付, 验 证性实验占主导, 综合性、设计性实验难以 落实; 实验教师地位相对较低, 个人专业能 力难以提升; 工程训练强度不够, 与生产现 场脱离严重, 学生感受工程现场氛围和接触 工程设备的机会少之又少。虽然高校推出了 多样化的课外科技创新活动, 但毕竟受益面 有限。校外生产实习环节, 本来是学生接触 社会的好机会, 但受各方面因素影响, 生产 实习出现形式主义。一是实习时间压缩, 甚 至学生实习分散不集中;二是实习安排学生 走马观花地参观，没有真正参与企业实践。 高校不能给学生提供充分的工程训练, 导致 学生缺少对工程设计和运用综合知识解决 问题的理解, 造成应用能力缺失。

\section{4 课堂教学方法落后: 听中学还是做中 学}

我国工程教育主要实施以教师为中心、 课堂讲授为主的教学模式。在教学方法上, 传统讲授法一直在高校课堂教学中发挥主 导作用, 中国的学生基本是在 “听中学”。 不可否认, 课堂讲授教学法对于缓解教学资 源紧张, 批量培养大学生起到不可忽视的作 用。但是随着高等教育的分流, 因材施教、 个性化培养人才的呼声愈来愈高, 以讲授为 主的教学方法已落后于时代的要求, 存在严 重的弊端, 体现在: 一是在知识与能力的关 系上, 过于注重专业知识灌输而忽视大学生 的能力培养; 二是在教与学的关系上, 强调 教师向学生灌输知识、信息而忽视大学生学 习上的独立性。构建主义认为, 只有学习者 根据情景主动构建的知识才最可靠, 工科专 业的教学方法迫切需要引入 “做中学”, 让 学生自己去构建知识。课程教学模式、教学 方法改革是全面提高教育教学质量的关键, 亦是目前教学改革瓶颈所在。

\section{5 教师工程背景薄弱: 如何授人以渔}

优秀的工程师培养依赖于一支高素质 特别是具有工程实践素质的教师队伍。高校 扩招后各大学大量引进青年教师, 他们虽拥 有高学历和科研经历, 但大多数没有在企业 锻炼过, 没有实际工程经历。许多教师从学 校到学校, 从讲台下的学生身份很快转变到 讲台上的教师身份, 没有受到足够的工程培 训就直接承担繁重的教学任务, 普遍缺乏对 工程教育进行系统的研究, 缺少对实际工程 经验的积累。而学校缺乏促进教师企业锻炼 的激励机制, 普通教师很少能长时间在企业 培训或进修。教师工程实践能力的缺乏, 直 接影响到他们在课堂上只能枯燥地讲授理 论而鲜有工程实例, 不能积极引导学生去体 验和思考, 必然难以启发学生学习兴趣, 课 堂教学质量堪忧。在工科教师尚且缺乏工程 实践经验的情况下, 如何做到授人以渔呢?

\section{3. 高等工程教育存在问题归因分析}

综上所述, 我国高等工程教育存在诸多 问题, 主要表现为没有处理好三对关系。其 一, 没有把握好科学教育和工程教育的关 系, 把科学教育混同了工程教育; 其二没有 处理好理论和实践的关系, 片面重视了理论 教学的作用, 轻视实践教学环节; 其三没有 处理好高校和社会的关系, 过分强调了高校 独立培养, 忽视了社会企业在培养人才中的 作用。

高等工程教育存在问题深层次原因有 两个:第一社会缺乏科学的高等工程教育评 价体系。目前以科研为导向的工程教育评价 体系, 过于重视科学研究成果的评价。在教 师的考核、晋升和职称评定时, 强调以三大 索引为指标的科研论文发表和纵向课题研 究数量; 在师资引进上, 看重科研成果, 弱 化教师教学水平, 对教师的工程实践经历不 作硬性要求。其结果使高校重理论, 轻实践, 背离了工程教育的本质特征“应用性”和“实 践性”。第二产学研合作缺乏适宜的外部配 套环境，整体上高校和企业关系疏离。国家 没有专门的产学研合作立法, 企业在人才培 养中的作用没有得到充分发挥。 


\section{4. 高等工程教育改革战略选择}

如何提高工程教育人才培养质量, 以适 应全球化背景下人才需求, 我们需借鉴国外 工程教育经验, 结合我国实际具体情况, 制 定出符合国情、科学合理的应用型人才培养 模式是我们当今工程教育改革的战略选择。

\section{1 高等工程教育从工程科学回归到工 程实际}

20 世纪 80 年代以来, 美国工程教育界 掀起了工程更教育要从工程科学回归到工 程实际的 “回归工程” 的思潮。回归工程是 在大工程观的思想指导下，重构工程教育， 强调工程实践能力的培养和工程学科课程 体系的整合。其中重要的是将工程人才培养 置于经济、社会、人文、生态等为一体的大 背景下, 培养学生的工程意识、工程素质和 工程能力 ${ }^{3}$ 。从当前我国高等工程教育的人 才培养现状来看, 对培养工程师的使命反而 弱化, 这与现实社会需求极不相符。

在当今科技革命时代, 工程教育必须真 正面向工程实际。高等教育回归工程包括培 养目标和培养模式的回归。在培养目标上, 由学术性的工程人才培养转向工程应用型 人才培养为主; 在培养方案上, 课程设置反 映社会需求, 教学内容能更多跟踪于技术发 展趋势, 加入更多的实践教学环节; 在教学 方法上, 加强文理学科交叉渗透, 培养学生 从多学科的角度, 系统的观点去解决工程实 际问题; 在师资队伍培养上，建立有利于形 成双师型教师队伍的发展机制，使教师到企 业锻炼成为一种常态。总之教育回归工程教 育就是要确立实践育人的教育理念, 把实践 贯穿于人才培养的全过程。

\section{2 教学模式以学科为导向转向以项目 为导向}

以学科为导向的工程教育课程教学模 式与工程实践脱节, 培养的工科学生知识单 一、创新精神与实践能力缺乏。课程教学模 式改革要求把传统的 “以教师为中心” 的教 学观念转变为“以教师为主导、学生为主体” 的教学观念; 通过精心设计有效的课程教学 方案, 灵活运用多样化的教学方法, 合理实 施多元化的考试评价方式, 探索提高课堂教
学质量的途径。CDI0 工程教育是近年来国 际工程教育改革的最新成果。汕头大学引进 这种教学模式并发展。中国在教育部的推动 下至今已经有超过 100 所高等院校全面接 受了 $\mathrm{CDIO}$ 人才培养模式的培训 ${ }^{4}$ 。CDIO 强 调从做中学, 主要做法是以工程项目设计为 导向来组织课程, 这样课程组织由过去单独 的学科知识一个维度转变为项目、知识、能 力相结合的三维架构。工程项目设计不仅注 重技术的学习, 更重要的是其中贯穿经济、 社会甚至历史文化的因素。通过项目设计进 行系统化的学习, 使学生学会发现问题、分 析问题、解决问题、与人沟通和团队合作 ${ }^{5}$ 。

工程教育改革必须改革教学模式，以

“项目实现” 作为教学的纽带, 在教学中注 重学生沟通、交流能力和系统的思维。将工 程实际问题带入课堂, 并由企业工程师和高 校教师共同带领学生按照实际工程项目的 要求进行课堂训练, 在实践中培养学生的自 主学习能力、工程应用能力以及创新能力。 当然 CDIO 只是解决当前工程教育人才培养 困境的一种答案，对于不同国家、不同层次 类型的学校会有参考借鉴价值。

\section{3 人才培养以高校为主转向产学合作}

欧美发达国家在产学合作教育方面已 有上百年的持续发展历史, 积累了丰富的经 验。国际上有 43 个国家的 1500 多所大学设 有合作教育项目。美国合作教育是理论与实 践有机结合的典范, 它使学生、学校和企业 之间形成一种合作关系, 三者均可从中受 益。在全美 3000 多所高校中有 1 / 3 实施这 种模式, 出现了一批以合作教育为特色、在 美国甚至在世界上都有一定影响的大学, 比 如辛辛那提大学、东北大学、加州州立理工 大学等。加拿大几乎所有的高校都实施这种 模式。滑铁卢大学拥有世界上规模最大的、 综合性最强的合作教育项目, 它连续 15 年 被评为加拿大最有创造性和总体评价最好 的大学。德国实行 “双元制” , 教学活动在 企业与高校交替进行, 要求工科大学生在入 学前要有不少于 1 年的工程训练经历, 在应 用科技大学 6 年内, 有一半时间在企业进行 工程训练和 1 年以上的毕业设计。发达国家 的发展规律表明校企协同是推动工程教育 与社会经济发展的必由之路, 同时也揭示了 
校外实践需要良好的外部环境和内部运行 机制。

\section{5. 结束语}

建构主义强调获取知识过程中的社会 互动性与真实情境性, 强调学生对知识的主 动探索、主动发现与主动建构。要培养优秀 工程人才, 需要利用学校、企业和科研机构 等多种不同教育环境和资源, 并充分发挥在 人才培养方面的独特优势, 把学校教育与在 企业锻炼有机结合。工程教育要适应社会发 展, 加强与产业联系, 创新人才培养模式。 通过产学合作, 使校内培养与校外培养相结 合, 共享企业资源, 扩大高校办学场地, 扩 大学生实践空间; 根据社会形势和技术发展 趋势及时更新课程教学内容, 调整人才培养 方案, 使人才培养更适应社会需求。总之我 们需要借鉴西方产学合作教育的经验, 以市 场为导向, 充分发挥高校、企业两个主体在 人才培养方面的优势, 优势互补、利益共享, 通过产学合作、工学结合的方式, 大力提高 高校人才培养质量和企业市场竞争力, 促进 高等工程教育和社会可持续发展。

\section{致谢}

本文系广西教改工程项目“基于卓越人 才培养的高校产学合作教育运行机制的研 究” (编号: 2012JGZ115) 阶段性研究成果。

\section{References}

[1] Luo yun. The discussion of reforming China's talents training mode in higher engineering education [j]. Journal of Nanjing University of science and technology (Social Science Edition), 2006 (6): 64-68

[2] Wei Yinxia. Guo Qing. The analyzed of reforming higher engineering talents training mode to adapt to industry demand. [j]. Education and Employment, 2011:40-41

[3] Xie Xiaozhen. The analyze of the meaning and essential characteristics of
"View of great works" [j]. Higher Engineering Education Research , 2008 (3): $35-38$

[4] Data from China CDIO website, http://www.chinacdio.CN

[5] Niu Huanxia, Interpretation of engineering education: the perspective of curriculum theory [j], Modern Education Science 2010 (6): 40-43 